\title{
Training and employment in Canada
}

\author{
An introductory guide
}

\author{
Steve Kisely and Judy Jones
}

\begin{abstract}
Provious articles have decit with aspects of training in Conada (Ereen, 1985), and in particular arrangements that exist for UK trainees to undertake a year's experience in Nova Scotia (Munro of al 1987). In adciltion, there have been accounts of troinees' experiences in particular settings (Ferguson, 1989; Colo, 1992). Procedures required to enter Conada to practise peychiatry are complex and involve general and specialist medical regitration alcensure to practise and certilication as a speciallat), remunoration and immigration procedures. This afticle is on introductory oulde and highlights recent changes in registration and postoraduate training.
\end{abstract}

\section{The Canadian health service}

Canada has a federal constitution and consists of 10 provinces and two northern territories. Health is a provincial responsibility, although the federal government contributes funds and sets national standards. As a result, provincial Departments of Health can organise health services quite differently from their neighbours. The authors' own experience is of New Brunswick which is one of the Maritime provinces that stretch along the Atlantic seaboard to the United States border.

The Canadian health system is a publically funded provider of services. Both individual psychlatrists in office practice and larger institutions such as hospitals are remunerated by the government via fixed fee-for-service payments or other alternate funding plans. Provincial governments therefore exert considerable influence on medical practice through purchasing or remuneration policies.

\section{Licensing or registration procedures}

There are three bodies that govern the practise of medicine in English speaking Canada outside Quebec: the Provincial medical licensing authorities; the Royal College of Physiclans and Surgeons of Canada; and the Medical Councll of Canada.
Each province is independently responsible for the registration or 'licensing" of medical practithoners through Medical Boards, and Counclls or Colleges of Physicians and Surgeons. There is no common set of requirements, portability or reciprocity so that a licence obtained in one province is not valid in another, even in the case of Canadian trained physicians. This is in marked contrast to Australia where there is portability of medical registration between different states (Kisely, 1993).

With the exception of Quebec, the determination of specialist medical qualifications is governed by the Royal College of Physicians and Surgeons of Canada. However, under provincial mental health legislation, it is possible for foreigntrained psychiatrists to obtain specialist recognition in some provinces.

The Medical Council of Canada has as one of its goals the promotion and administration of a medical qualification known as the licentiate of the Medical Council of Canada (LMCC). This is granted to graduate physicians who have passed the two parts of the Qualifying Examination (MCCQE) and completed one year of postgraduate training. In practice, one year of postgraduate medical training taken anywhere in the world will usually be accepted. Foreign trained medical graduates must pass an Evaluating Examination (MCCEE) before they are eligible to sit the Qualifying Examination.

In summary, acquisition of the LMCC is dependant on passing the MCCQE Part II. Sitting the MCCQE Part II is dependant on passing MCCQE Part I and completing one year of postgraduate training. Sitting the MCCQE Part I is dependant on passing the MCCEE, and sitting the MCCEE is dependant on possession of a medical degree.

\section{Medical services and manpower}

Although, in the past, many British trained doctors have been recruited to work in Canada, the rapid expansion in medical school numbers 
in the sixties and seventies means that the demand for medical manpower can now largely be met domestically. Within Canada, even Canadian physicians face restrictions on their rights to work in provinces other than where they trained. Such restrictions include limitations of access to hospital facilities or remuneration entitlements. This has resulted in increasing difficulties for overseas medical graduates intending to work in Canada.

In spite of this, Canada still suffers from a shortage of psychiatrists, especially in the Government run sector. This is due to the maldistribution of the available manpower in the speciality, with the majority of psychiatrists being engaged in general hospital or private office practice in the large urban areas. By contrast. less prosperous or isolated areas such as the Maritime provinces (Newfoundland, Nova Scotia. New Brunswick and Prince Edward Island), or Labrador and the Northwest Territories and the northern parts of most provinces remain short of psychiatrists. In 1986, the 25\% of Canada's population that lived in rural communities of 10000 people or less were served by only $3.6 \%$ of the total number of psychiatrists in the country (el-Guebaly et al, 1993).

\section{Training}

Training in all clinical specialities is overseen by the Royal College of Physicians and Surgeons of Canada. As in Britain, this is undertaken in training programmes which are accredited by the College (Royal College of Physicians and Surgeons of Canada). However, the untversity affiliation is much stronger in Canada. Trainees or 'residents' must be registered in an accredited postgraduate training programme in one of the 16 medical schools in the country. Medical students apply directly to the speciality programme of their choice during their third year. After one year's experience in general medicine, psychiatric trainees enter four years of speciality training. The mandatory 'core' requirements, usually taken in the first two years include twelve months of 'adult general hospital psychiatry', six months of child and adolescent psychiatry and six months of the study, care and rehabilitation of chronic psychotic patients. The other two years may include six to 12 months in an appropriate sub-speciality, including research or basic sciences. Other requirements include at least two years of supervision in short- and long-term psychotherapy, as well as consultation-liaison and old age psychiatry.

As in Australia (Kisely, 1993), the Fellowship of the College (FRCP(C)) is an 'exit' examination which marks the end of training. This is in two parts. The first written examination (part 1) consists of 150 multiple choice questions (MCQs), short answer questions (SAQs), and short essay questions (SEQs). In 1995 the number of MCQs will increase to 175 . Finally, after success in the 'writtens' (part 1) there is an oral examination based on an observed 50-minute interview with a single patient, followed by a one hour oral examination on the interview which may include general patient management questions.

\section{Working in Canada}

Canada offers considerable progressional and financial opportunities and it is often possible to develop new services in a way that is impossible in the United Kingdom.

There are three hurdles to arranging to work in Canada, which vary in difficulty according to whether temporary work experience or permenant settlement are contemplated: medical registration or 'licensure', work permits and special recognition or 'certification'.

These three areas are closely interrelated and prospective applicants will find it difficult to surmount the attendant difficulties without sponsorship from prospective employers. In addition, the rapidity of changes to the policies and regulations within these areas and their complexity mean that considerable background research should be undertaken.

The granting of temporary or permanent residency in the country is the responsibility of the Federal government through citizenship, landed immigrant status and employment authorisations (work wise). Work permits for temporary or permanent work must be obtained through the Canadian High Commission in London. Work permit applications must be accompanied by evidence of eligibility for a licence to practise and require sponsorship from prospective employers. A recommendation from the relevant provincial Ministry of Health may also be required. If a permanent post is contemplated it is advisable to ask employers for sponsorship for 'landed immigrant status' before leaving the United Kingdom. This confers important benefits for doctors and their families in terms of health care and social security entitlements which are not available if entrance to the country is gained through a temporary work permit. Accompanying spouses and dependants of landed immigrants automatically obtain the same status provided they are included in the original application.

Detalls of positions for trained psychiatrists can be obtained through senior colleagues with contacts abroad, contacting prospective employers directly or the pages of the medical press. The Canadian Psychiatric Association (CPA) publishes a comprehensive guide to employment opportunities which is obtainable from the CPA. 
200-237 Argyle, Ottawa, Ontario K2P $1 B 8$ (Canadian Psychiatric Association). In the case of New Brunswick, the best point of contact would be the Department of Human Resources, PO Box 3220, Postal Station B, St John.

British medical degrees have not been sufficient for registration purposes in Canada for some time, although there may be more flexibility in Newfoundland.

Some employers will therefore expect that overseas doctors should pass a screening examination (the Evaluation Examination of the Medical Council of Canada (MCCEE)) which consists of two multiple choice question papers covering all aspects of clinical medicine. This is held twice a year in London and other places in the world, and application forms for the examination in Britain are available from the Canadian High Commission.

\section{Temporary experience}

The optimum time for temporary overseas experience as part of UK psychiatric training is probably as part of a senior registrar rotation. It is usually possible to arrange a year's absence with the guarantee of a continued place on the UK scheme. In addition, one year of overseas experience will usually count as part of higher specialist training on application to the Joint Committee on Higher Psychiatric Training. Advice on this point is best sought in advance.

\section{Permanent settlement}

Doctors wishing to settle permanently may face two additional hurdles; the FRCP(C) in psychiatry and the Qualifying Examination of the Medical Council of Canada (MCCQE).

In provinces such as Nova Scotia and New Brunswick it is possible to obtain limited medical registration while in government employment on the strength of the MRCPsych and the MCCEE. Most employers, however, appear to expect that doctors should pass the Canadian fellowship examination (FRCP(C)). Some will only offer a permanent position, and support for permanent residence or 'landed immigrant status', when a doctor has acquired Canadian Fellowship.

In order to sit the fellowship examination (FRCP(C)), individuals who are graduates from medical schools outside North America must have passed the MCCEE or MCCQE, or one of the screening examinations from the United States. In addition, candidates must apply for recognition of overseas training by the Canadian College which involves providing details of qualifications, all medical posts and references from previous supervisors. This can be done before entering the country and many employers will not contemplate recruiting an individual from overseas unless their training has been formally approved by the College. The cost of this will often be reimbursed by a prospective employer. A formally expedited assessment is avallable at the request of the Dean of a Canadian medical school, or the medical director of a Canadian hospital and can reduce the time to consider the application by several months.

If previous experience is approved by the College, it is possible to take the first part of the examination at the next sitting held once a year in early September. The College will not, however, give recognition for training completed more than seven years before the application for assessment and it is virtually impossible for overseas doctors to obtain a Canadian postgraduate training position. Newly arrived doctors who are eligible to sit the FRCP(C) are usually given support by employers, including attendance at revision courses to help prepare for the examination. Such support is essential as there are differences in the content and emphasis of psychiatric training between the UK and Canada. Psychiatrists who hold the MRCPsych should not assume they will be automatically successful at the Canadian examinations.

Often this will be sufficient to gain a permanent position and permanent residence but there may be continuing restrictions to practise, and it may be increasingly difficult to subsequently move to another province, just as for Canadian physicians.

Passing the Qualifying Examination of the Medical Council of Canada (MCCQE), which is equivalent to Final MB ChB, confers greater mobility but must be accomplished within 5 years of obtaining the MCCEE. This leads to enrolment on the Canadian medical register as a licentlate of the Medical Council of Canada (LMCC). However, as registration in individual provinces depends on the provincial medical licensing authorities, even this qualification does not guarantee an unrestricted medical licence.

Given the fluidity and complexity of the situation, exact details should be clarified through the appropriate provincial medical licensing authority, and the Medical Council of Canada. Prospective migrants should carefully investigate the means of obtaining a full licence in the particular province to which they are seeking to relocate so as to enable them to engage in independent practise. Alternatives such as hospital or restricted licences for those in service posts, or academic licences for doctors appointed at the rank of Assistant Professor or higher, may be invalid for any other position than the one for which the licence was originally granted.

\section{Conclusions}

In summary, the usual requirements for working in Canada are 
- a licence or certificate to practise from the appropriate provincial medical licensing authority

- an offer of employment from a Canadian employer

- completion of the immigration process, including a medical examination and interview.

A recommendation from the particular provincial Ministry of Health may also be required.

Registration, specialist recognition and work permits are inter-linked and often progress in one area is affected by the situation in another. In addition, provincial governments have attempted to control the movement of Canadian trained medical practitioners within the country through restrictions on remuneration or rights to practise granted to those coming from outside the particular province in question.

Working in a country with cultural and geographical diversity can certainly be recommended on a temporary basis. Settling on a more permanent basis requires a great deal of patience and hard work, but many prospective employers will offer considerable assistance. The financial rewards for those who persist can be considerable, especially for junior psychiatrists who are within seven years of having completed training and who are eligible to take the FRCP(C) examination.

Psychiatrists considering a permanent move should carefully scrutinise both the posts and restrictions to practise before committing themselves to positions. Geographically isolated facilities, which cannot attract Canadian applicants may well be able to offer fast track routes into the country. However, once employed, doctors may find themselves trapped by restrictions on the location, speciality and autonomy of practice. In addition, those contemplating a permanent move should negotiate sponsorship for "landed immigrant status' with prospective employers.

\section{Useful addresses}

Canadian Psychiatric Association, 200-237 Argyle, Ottawa, Ontario K2P 1B8, Canada

The Royal College of Physicians and Surgeons of Canada, 774 Promenade Echo Drtve, Ottawa, Ontario K1S 5N8, Canada

Canadian High Commission, Immigration Section, 38 Grosvenor Street, London W1X OAA

The Medical Council of Canada, Box 8234, Station T, Ottawa, Ontario K1G 3H7, Canada

\section{References}

Canadian Psychiatric Association (1994) Opportunities/ Perspectives. Ottawa: Canadian Psychlatric Association. el-Geubaly, N., Kingstone, E., RaE-Grant, Q., et al (1993) The geographical distribution of psychiatrists in Canada: unmet needs and remedial strategles. Canadian Journal of Psychiatry, 38, 212-216.

Green, C. M. (1985) British Psychiatrists in Canada. Bulletin of the Royal College of Psychiatrists, 9, 77-78.

Ferguson, B. (1989) The Canadian experience. Psychiatric Bulletin, 13, 499-500.

GOJER. J. (1992) Psychiatry in Northern Newfoundland and Labrador. Psychiatric Bulletin, 16, 784-785.

KISELY, S. R. (1993) Manpower, education and training in Australia. Psychiatric Bulletin, 17, 669-671.

MuNRO, A., MCCORMICK, W. O. \& ARCHIBALD, D. W. (1987) Achieving the BTC qualification. Psychiatric Bulletin. 11 , 305-306.

The Royal College of Physiclans and Surgeons of Canada (1993) General Information and Regulations on Training and Certification Requirements. Ottawa: the Royal College of Physiclans and Surgeons of Canada.

Steve Kisely, Lecturer in Public Health Medicine, and Judy Jones, Lecturer in Public Health Medicine, School of Epidemiology and Health Sciences, University of Manchester, Oxford Road. Manchester M13 9PL 